\title{
Cross-Reactivity in Drug Hypersensitivity Reactions to Sulfasalazine and Sulfamethoxazole
}

\author{
Anna Zawodniak Priska Lochmatter Andreas Beeler Werner J. Pichler \\ Division of Allergology, Clinic for Rheumatology and Clinical Immunology/Allergology, Inselspital, University of \\ Bern, Bern, Switzerland
}

\section{Key Words}

Aromatic sulfonamides $\cdot$ Cross-reactivity .

Sulfamethoxazole $\cdot$ Sulfasalazine $\cdot$ Sulfonamide allergy

\begin{abstract}
Background: Sulfonamides are generally classified into 2 groups: antibiotics and non-antibiotics. Recent studies showed that patients allergic to sulfonamide antibiotics do not have a specific risk for an allergy to sulfonamide non-antibiotic. However, the anti-inflammatory drug sulfasalazine represents an important exception. Used in rheumatic diseases, it is classified as a non-antibiotic sulfonamide, but is structurally related to antibiotic sulfonamides. Therefore, we aimed to analyze in vitro the cross-reactivity between the antimicrobial sulfamethoxazole and the anti-inflammatory drug sulfasalazine. Methods: PBMC from 2 patients with severe hypersensitivity syndrome to sulfasalazine, 3 patients with sulfamethoxazole allergy and 5 healthy donors were isolated and incubated with medium only (negative control), 2 concentrations $(10,100 \mu \mathrm{g} / \mathrm{ml})$ of sulfapyridine, 2 concentrations $(100,200 \mu \mathrm{g} / \mathrm{ml})$ of sulfamethoxazole, and tetanus toxoid $(10 \mu \mathrm{g} / \mathrm{ml})$ as a positive control. After 6 days of culture, ${ }^{3} \mathrm{H}$-thymidine was added and cell proliferation was measured. Results: In all patients tested, the lymphocyte transformation tests were positive for both sulfapyridine and sulfamethoxazole, suggesting a strong cross-reactivity to these drugs. None of the healthy donors reacted to any of the drugs tested. We refrained from provoking our patients with
\end{abstract}

either sulfasalazine or sulfamethoxazole, as they had a clear, typical history, severe symptoms and were positive on in vitro tests to both compounds. Conclusions: We demonstrate that in the case of sulfamethoxazole and sulfasalazine, crossreactivity is dependent on chemical features rather than the indication of the drugs. Therefore, patients with hypersensitivity to sulfasalazine or sulfamethoxazole should be specifically advised to avoid both drugs.

Copyright $\odot 2010$ S. Karger AG, Basel

\section{Introduction}

Sulfonamide-containing antimicrobials are known causes of drug hypersensitivity reactions [1], and are strongly associated with most severe, life-threatening events [2]. Sulfonamide structures $\left(\mathrm{SO}_{2}-\mathrm{NH}_{2}\right)$ are included in a variety of drugs, some with antibiotic features (e.g. sulfamethoxazole), others acting as diuretics, antidiabetics or analgesics. In rheumatology, the Cox 2 inhibitor celecoxib and the anti-inflammatory drug sulfasalazine contain sulfonamide structures and are still widely used. Any side effect to these drugs was until recently summarized under the unfortunate term 'sulfa allergy' and patients with a presumed 'sulfa-allergy' were advised to avoid any sulfonamide containing drug. However, epide-

\section{A. Zawodniak and P. Lochmatter contributed equally to this work.}

\section{KARGER}

Fax +41613061234

E-Mail karger@karger.ch

www.karger.com
(C) 2010 S. Karger AG, Basel

$1018-2438 / 10 / 1532-0152 \$ 26.00 / 0$

Accessible online at:

www.karger.com/iaa
Correspondence to: Prof. Werner J. Pichler

Division of Allergology

Clinic for Rheumatology and Clinical Immunology/Allergology

Inselspital, University of Bern, $\mathrm{CH}-3010$ Bern (Switzerland)

Tel. +41 31623 2264/3174, Fax +41 31623 2747, E-Mail werner.pichler@insel.ch 
miological [3-5], in vitro and skin test studies [6, 7] pointed out that true allergy secondary to cross-reactivity of sulfonamide antibiotics and non-antibiotics is unlikely to occur. The chemical differences between these two drug classes are too big, therefore, cross-reactivity occurred only within the group of aromatic sulfonamides $[8,9]$. As these are mainly used as antibiotics (sulfamethoxazole, sulfadiazine, sulfisoxazole), clinicians tend to differentiate between allergy to antibiotic sulfonamides and allergy to non-antibiotic sulfonamides. In case of allergic reaction to an antibiotic sulfonamide (mostly elicited by sulfamethoxazole), the non-antibiotic sulfonamides could be used.

In this report we would like to remind that this distinction between antibiotic and non-antibiotic sulfonamides is misleading, as cross-reactivity is not due to the function but the structure of the compound. An important example for an aromatic sulfonamide not used as an antibiotic is the anti-inflammatory drug sulfasalazine. It is a prodrug which is split in the colon by the bacterial enzyme azoreductase in 5-aminosalicylic acid and the aromatic sulfonamide sulfapyridine (fig. 1) [10]. Sulfasalazine can cause severe even lethal hypersensitivity reactions, which are mainly due to sulfapyridine and are probably related to the generation of sulfapyridine-specific T cells.

We analyzed 5 patients with allergic reactions to either sulfasalazine or sulfamethoxazole for potential cross-reactivity to these 2 compounds.

\section{Methods}

The patients were analyzed in clinical remission of their drug allergy and were healthy. All patients were part of a study by Lochmatter et al. [11]. Two patients had severe hypersensitivity syndromes involving skin and liver, 1 developed a severe bullous skin disease and 2 had a severe exanthema. Offending drugs were determined based on positive in vitro tests and clear medical history (clear temporal relationship between starting the drug and development of reaction, and typical clinical symptoms; table 1). Five healthy donors without history of drug hypersensitivity but responsive to tetanus toxoid (TT) served as controls. All patients gave informed consent. The study was approved by the local ethical committee.

Non-toxic concentrations of the following antigens were used for in vitro stimulation: sulfamethoxazole (Hoffman-La Roche, Basel, Switzerland), amoxicillin, sulfapyridine, furosemide and hydrochlorothiazide (Sigma, Buchs, Switzerland). TT (BernaBiotech, Bern, Switzerland) was used as a positive control.

For the lymphocyte transformation test (LTT), PBMC from patients and healthy controls were cultured for 6 days $\left(37^{\circ} \mathrm{C} ; 5 \%\right.$ $\mathrm{CO}_{2}$ ) with culture medium alone (negative control), with two
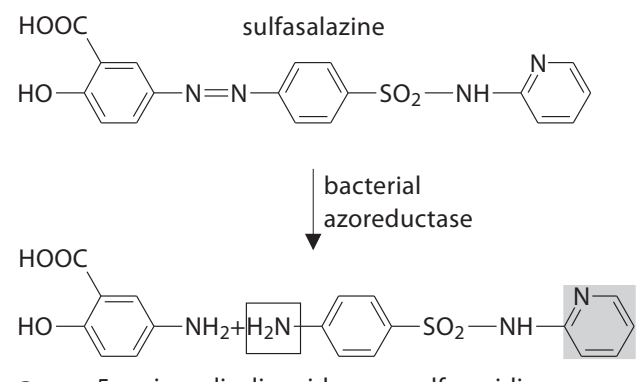

a 5-aminosalicylic acid sulfapyridine

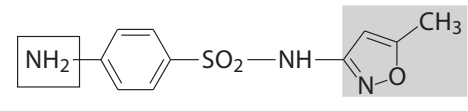

sulfamethoxazole

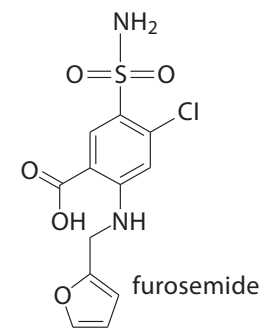

c

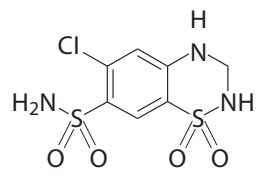

hydrochlorothiazide

d
Fig. 1. Cleavage of sulfasalazine into sulfapyridine and 5-aminosalycilic acid. Sulfasalazine (a) is not active in its ingested form but broken down by colon bacterial enzyme azoreductase into 2 products: 5 -aminosalicylic acid and sulfapyridine. Sulfapyridine and the structurally related sulfamethoxazole (b) containing an aromatic amine group at the N4 position (box) and a substituted ring at the N1-position (highlighted in grey) are both aromatic sulfonamides and can induce strong $\mathrm{T}$ cell responses resulting in a severe drug hypersensitivity reaction. Furosemide (c) and hydrochlorothiazide (d) are both non-aromatic sulfonamides and do not cross-react with sulfapyridine and sulfamethoxazole.

drug concentrations or with TT (positive control). Thereafter, 0.5 $\mu \mathrm{Ci}{ }^{3} \mathrm{H}$-thymidine was added for $14 \mathrm{~h} .{ }^{3} \mathrm{H}$-thymidine incorporation was measured in a $\beta$-counter (Trace96; Inotech, Wohlen, Switzerland). Stimulation indices (SI) were calculated as counts per minute (cpm) with antigen divided by cpm in culture medium. SI = 2 was considered as a cut-off point for positivity.

For statistical analysis Mann-Whitney test with $\alpha=0.05$ was used. $\mathrm{p}<0.05$ were considered statistically significant. 
Table 1. Patients' characteristics

\begin{tabular}{|c|c|c|c|c|c|c|c|c|}
\hline $\begin{array}{l}\mathrm{Pa}- \\
\text { tient } \\
\text { No. }\end{array}$ & $\begin{array}{l}\text { Age } \\
\text { years }\end{array}$ & Sex & Disease & Culprit drug & $\begin{array}{l}\text { Time interval between } \\
\text { starting the therapy and } \\
\text { allergic reaction }\end{array}$ & $\begin{array}{l}\text { Other medication } \\
\text { at the time of reaction }\end{array}$ & $\begin{array}{l}\text { Other drug } \\
\text { allergies }\end{array}$ & $\begin{array}{l}\text { Interval between } \\
\text { acute allergy } \\
\text { and testing }\end{array}$ \\
\hline 298 & 41 & female & DRESS & $\mathrm{SP}(+)$ & 4 weeks & Ciprofloxacin (-) & no & 6 months \\
\hline 38 & 48 & male & DRESS & $\mathrm{SP}(+)$ & 2.5 weeks & $\begin{array}{l}\text { Ceftriaxon (-) } \\
\text { Diclofenac (-) }\end{array}$ & no & 13 months \\
\hline 245 & 71 & male & SJS & $\operatorname{SMX}(+)$ & 10 days & $\begin{array}{l}\text { Ceftriaxon }(-) \\
\text { Clarythromycin }(-)\end{array}$ & no & 2 months \\
\hline 11 & 45 & male & MPE, malaise & $\operatorname{SMX}(+)$ & 12 days & no other medication & no & 12 years \\
\hline 32 & 64 & male & erythroderma & $\operatorname{SMX}(+)$ & 10 days & $\begin{array}{l}\text { multiple drug } \\
\text { hypersensitivity }\end{array}$ & $\begin{array}{l}\text { phenytoin } \\
\text { amoxcillin }\end{array}$ & 19 months \\
\hline
\end{tabular}

(+) LTT positive, (-) LTT negative. DRESS = Drug reaction with eosinophilia and systemic symptoms; MPE = maculopapular exanthema; SJS = Stevens Johnson syndrome; SP = sulfapyridine; SMX = sulfamethoxazole.

\section{Results}

As shown in figure 2, all drug-allergic patients tested on LTT with sulfamethoxazole and sulfapyridine (the sulfanilamide component of sulfasalazine; fig. 1) were positive to both aromatic sulfonamides, suggesting strong cross-reactivity. These reactions were drug-specific, as the patients did not react to the unrelated drugs, and none of the healthy donors reacted to any of the drugs tested. Both allergic and healthy donors reacted vigorously to the control antigen TT. In 4 out of 5 tested patients, stimulation indices were higher after stimulation with sulfamethoxazole than sulfapyridine regardless of which drug had caused the allergic reaction. The proliferation in response to both culprit and cross-reactive drugs in patients was significantly increased $(p=0.0007-0.008)$ compared to healthy controls, but there were no significant responses to the unrelated drugs $(\mathrm{p}=0.21-0.9)$. We abstained from provoking our patients with either sulfasalazine or sulfamethoxazole, as they had a clear history and severe, even life-threatening, symptoms which makes provocation tests superfluous.

\section{Discussion}

Due to the widespread use of sulfonamide drugs and the comparably common occurrence of hypersensitivity reactions to some of these compounds, a possible crossreactivity of immune reactions to sulfonamides is of great clinical interest.
Several epidemiological and in vitro studies have demonstrated that cross-reactivity between aromatic sulfonamides and non-aromatic sulfonamides is highly unlikely [3-7]. The most reassuring evidence comes from a retrospective cohort study [3], which showed that individuals who had documented allergic reactions to a sulfonamide antibiotic indeed reacted more commonly to non-antibiotic sulfonamide drugs. However, the same individuals reacted to the pharmacologically distinct class of penicillins even more often. This suggests that patients with a history of allergic reaction to antimicrobial sulfonamides may be generally at increased risk for reaction to other drugs, and there is no need to specifically avoid non-antibiotic sulfonamides. Even in this carefully conducted reference study, sulfasalazine was classified as non-antibiotic and noncross-reactive with aromatic antibiotic sulfonamides.

Aromatic sulfonamide antibiotics contain an aromatic amine group at the $\mathrm{N} 4$ position and a substituted ring at the N1-position (fig. 1). This substituted ring is not present in non-aromatic amines such as furosemide, thiazide diuretics, antidiabetics and celecoxib but is present in the anti-inflammatory drug sulfasalazine (sulfapyridine). These structural similarities explain the extensive cross-reactivity between the aromatic sulfonamides, which was demonstrated by evaluating sulfamethoxazole-specific $\mathrm{T}$ cell clones, murine $\mathrm{T}$ cell hybridoma cells transfected with sulfamethoxazole-specific $\mathrm{T}$ cell receptors and with PBMC. No reactivity to furosemide, glibenclamide or celecoxib was observed [8].

Here, we would like to emphasize that sulfasalazine, which is extensively used in the treatment of ulcerative colitis, proctitis, Crohn's disease, rheumatoid arthritis 
Fig. 2. Drug-specific proliferation in the lymphocyte transformation test. PBMC $\left(2 \times 10^{5}\right.$ cells/well $)$ of 5 drug allergic patients (a) and 5 healthy donors (b) were coincubated with 2 different concentrations of sulfamethoxazole (SMX, 100 and 200 $\mu \mathrm{g} / \mathrm{ml}$ ), sulfapyridine (SP, 10 and $100 \mu \mathrm{g} /$ $\mathrm{ml})$ and the unrelated drugs amoxicillin (AMX, 200 and $500 \mu \mathrm{g} / \mathrm{ml}$ ), furosemide (FRS, 10 and $50 \mu \mathrm{g} / \mathrm{ml}$ ) and hydrochlorothiazide (HCTZ, 10 and $50 \mu \mathrm{g} / \mathrm{ml})$. Culture medium and tetanus toxoid (TT, 10 $\mu \mathrm{g} / \mathrm{ml})$ served as negative and positive controls, respectively. Patients 295 and 38 had an allergic reaction to sulfasalazine, patients 11, 32 and 245 had a reaction to SMX. Positive stimulation index $(\mathrm{SI}=2)$ is indicated by the dashed line.

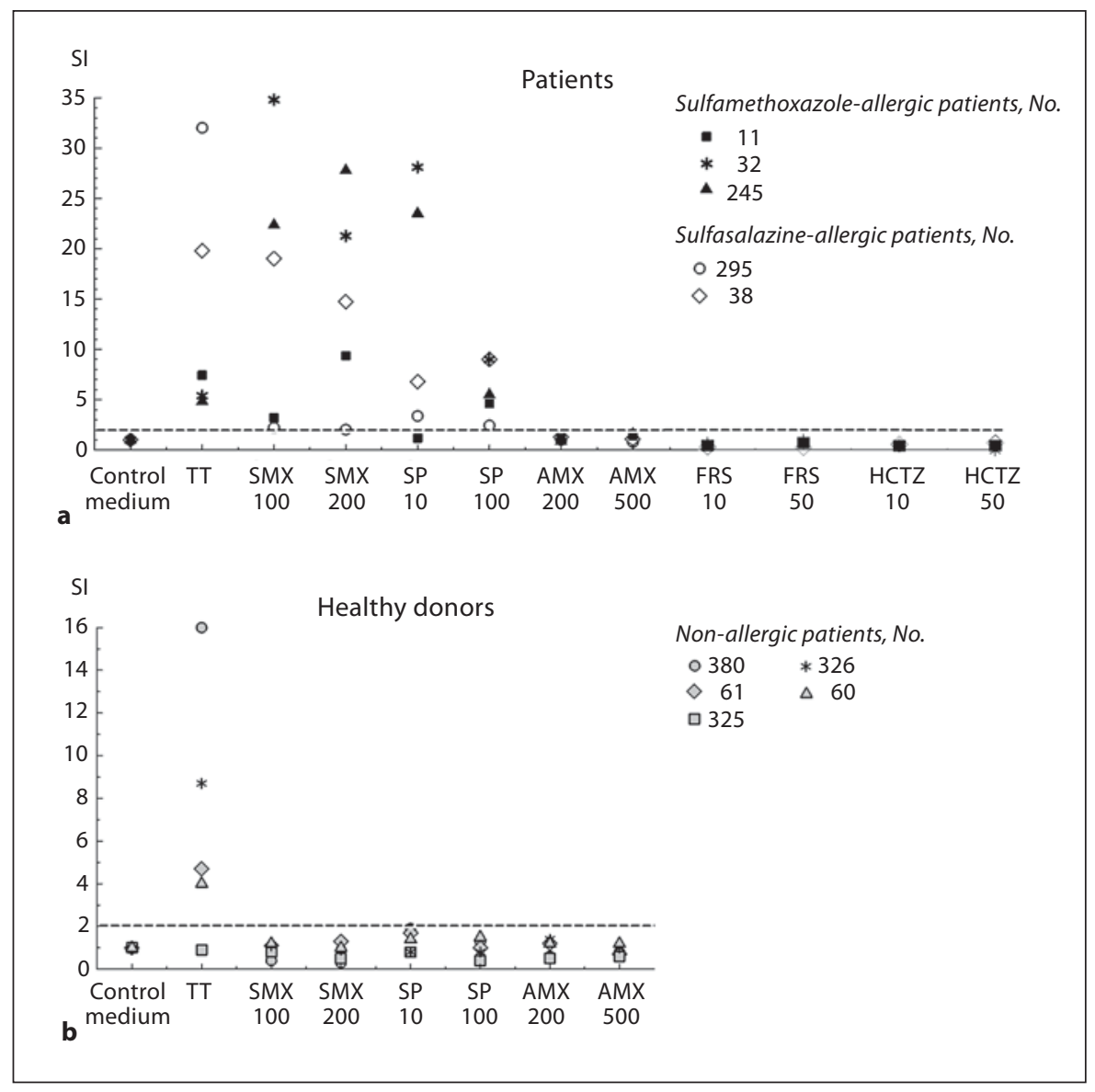

and ankylosing spondylitis, contains in fact an aromatic sulfonamide (fig. 1a), because it is a prodrug that is split in the colon by the bacterial enzyme azoreductase into 5aminosalicylic acid and the aromatic sulfonamide sulfapyridine (fig. 1).

We present 2 patients with severe hypersensitivity syndromes to sulfasalazine and 3 patients who originally had an allergic reaction to sulfamethoxazole. In all cases, the LTT were positive both to sulfapyridine and to the antibacterial drug sulfamethoxazole, confirming a strong crossreactivity of these drugs. In one patient (No. 295), only a weak response to sulfamethoxazole in both concentrations $(100 \mu \mathrm{g} \mathrm{SI}=2.23 ; 200 \mu \mathrm{g} \mathrm{SI}=2.02)$ was observed. This may reflect a lower amount of $\mathrm{T}$ cells able to cross-react with this particular compound in this particular patient.

We relied on in vitro results and abstained from provoking our patients with the sulfonamides (either sulfasalazine or sulfamethoxazole), as they had a clear and typical history, severe, even life-threatening symptoms and positive in vitro tests to both compounds. Moreover, other studies on the cross-reactivity of structurally related compounds in drug hypersensitivity showed a good correlation between in vivo tests and in vitro LTT [12-14] and LTT has been shown to have a high specificity of $>85 \%$ [15]. Taken together, these data support the concept that the positive LTT may be helpful to identify cross-reactive agents in certain drug groups but due to its limited sensitivity it cannot be used to rule out cross-reactivity.

As the structural similarity between the antibiotic sulfamethoxazole and the anti-inflammatory compound sulfapyridine contained in sulfasalazine is not so obvious for most clinicians, we find it prudent to advise patients with hypersensitivity to sulfamethoxazole to avoid sulfasalazine (and vice versa). For the safety of the patients, we recommend adding sulfasalazine to the allergy passport for patients allergic to sulfamethoxazole (and vice versa). This is all the more important as the respective $\mathrm{T}$ cell-mediated reactions can be life-threatening and cause severe generalized symptoms affecting the liver, lungs and other organs. 


\section{References}

1 Slatore CG, Tilles SA: Sulfonamide hypersensitivity. Immunol Allergy Clin North Am 2004;24:477-490, vii.

$>2$ Mockenhaupt M, Viboud C, Dunant A, Naldi L, Halevy S, Bouwes Bavinck JN, Sidoroff A, Schneck J, Roujeau JC, Flahault A: Stevens-Johnson syndrome and toxic epidermal necrolysis: assessment of medication risks with emphasis on recently marketed drugs. The EuroSCAR-study. J Invest Dermatol 2008;128:35-44.

$\checkmark 3$ Strom BL, Schinnar R, Apter AJ, Margolis DJ, Lautenbach E, Hennessy S, Bilker WB, Pettitt D: Absence of cross-reactivity between sulfonamide antibiotics and sulfonamide nonantibiotics. N Engl J Med 2003; 349:1628-1635.

4 Hemstreet BA, Page RL 2nd: Sulfonamide allergies and outcomes related to use of potentially cross-reactive drugs in hospitalized patients. Pharmacotherapy 2006;26:551557.

5 Brackett CC, Singh H, Block JH: Likelihood and mechanisms of cross-allergenicity between sulfonamide antibiotics and other drugs containing a sulfonamide functional group. Pharmacotherapy 2004;24:856-870.
6 Shapiro LE, Knowles SR, Weber E, Neuman MG, Shear NH: Safety of celecoxib in individuals allergic to sulfonamide: a pilot study. Drug Saf 2003;26:187-195.

-7 Tornero P, De Barrio M, Baeza ML, Herrero T: Cross-reactivity among p-amino group compounds in sulfonamide fixed drug eruption: diagnostic value of patch testing. Contact Dermatitis 2004;51:57-62.

8 Depta JP, Altznauer F, Gamerdinger K, Burkhart C, Weltzien HU, Pichler WJ: Drug interaction with T-cell receptors: T-cell receptor density determines degree of crossreactivity. J Allergy Clin Immunol 2004;113. 519-527.

9 von Greyerz S, Zanni MP, Frutig K, Schnyder $\mathrm{B}$, Burkhart C, Pichler WJ: Interaction of sulfonamide derivatives with the TCR of sulfamethoxazole-specific human ab+ T cell clones. J Immunol 1999;162:595-602.

10 Peppercorn MA, Goldman P: The role of intestinal bacteria in the metabolism of salicylazosulfapyridine. J Pharmacol Exp Ther 1972;181:555-562.
11 Lochmatter P, Beeler A, Kawabata TT, Gerber BO, Pichler WJ: Drug-specific in vitro release of IL-2, IL-5, IL-13 and IFN-gamma in patients with delayed-type drug hypersensitivity. Allergy 2009;64:1269-1278.

12 Lerch M, Keller M, Britschgi M, Kanny G, Tache V, Schmid DA, Beeler A, Gerber BO, Luethi M, Bircher AJ, Christiansen C, Pichler WJ: Cross-reactivity patterns of $\mathrm{T}$ cells specific for iodinated contrast media. J Allergy Clin Immunol 2007;119:1529-1536.

13 Torres MJ, Mayorga C, Cornejo-Garcia JA, Lopez S, Chaves P, Rondon C, Fernandez T, Blanca M: Monitoring non-immediate allergic reactions to iodine contrast media. Clin Exp Immunol 2008;152:233-238.

14 Lopez S, Torres MJ, Rodriguez-Pena R, Blanca-Lopez N, Fernandez TD, Antunez C, Canto G, de Luque V, Mayorga C: Lymphocyte proliferation response in patients with delayed hypersensitivity reactions to heparins. Br J Dermatol 2009;160:259-265.

15 Pichler WJ, Tilch J: The lymphocyte transformation test in the diagnosis of drug hypersensitivity. Allergy 2004;59:809-820. 